\title{
Metonymy Diversity Presence and Impact Analysis on Language Phenomenon under the Perspective of Cognitive Linguistics
}

\author{
Wang Jiaoyan \\ Foreign Languages Department, Jingchu University of Technology, Jingmen, Hubei, 448000, China
}

Keywords: Cognitive linguistics; Metonymy; Diversity presence; Language phenomenon

\begin{abstract}
The definition and understanding of metonymy have the characteristics of diversity under the perspective of cognitive linguistics. Compared with traditional rhetoric studied metonymy, metonymy under the perspective of cognitive linguistics is defined as a cognitive process and phenomenon. It is on the basis of people's cognition and appears diversified functions and features in language development. It has a great influence on the structure of language. Based on cognitive linguistics, we can more comprehensively understand the characteristics and function of metonymy. It can promote the diversification of language and enhance the expressing effect of language. This article analyzes metonymy diversity presence impact on language phenomenon under the perspective of cognitive linguistics.

Traditional linguistics research studies metonymy in the scope of literature and rhetoric. Metonymy, as a kind of important rhetoric, can achieve abundant expression effect applied in literature and show the readers a different feeling. So for a long time, the rhetorical function and language function of metonymy are emphasized [1]. But with the gradual development of cognitive linguistics, the research of metonymy is reconsidered, and there are different point of view discussions about it. It is not comprehensive only to study metonymy from one aspect. It will ignore many functions and features of metonymy. So the study of metonymy should be from the perspective of cognitive linguistics. Metonymy diversity characteristics and development trend are studied to analyze the effect of metonymy in language phenomenon.
\end{abstract}

\section{THE DEFINITION AND UNDERSTANDING OF METONYMY}

Metonymy was earliest known as antonomasia, etc. It was taken as rhetoric in traditional figures of speech, so experts and scholars included it in the field of rhetoric and use it as a representative name for something. People also call it metonymy. Under the perspective of cognitive linguistics, metonymy is researched in new areas. Under the perspective of cognitive linguistics, metonymy is different from the traditional rhetoric. Metonymy is not a language tool, but to study metonymy from the perspective of language ontology. Metonymy is taken as a common language phenomenon. Traditional rhetoric scholars include metonymy in the level of vocabulary study, and metonymy under the perspective of cognitive linguistics is in various languages, such as words, sentences and behavior. Under the perspective of cognitive linguistics, metonymy is often defined as a way of thinking of people. The way of thinking is based on people's practical experience and is according to certain principles and rules. It is a way of thinking and behavior in the practice. In simple terms, under the perspective of cognitive linguistics, metonymy is defined as a cognitive thinking mode. Under the perspective of cognitive linguistics, metonymy is a cognitive process and a process to realize a conceptual metaphor to an entity of the concept [2].

Through the understanding of metaphor definition above, it can be seen that scholars in different field have different definition of metonymy. Cognitive linguistics perspective metonymy also has different understanding and definition. Metonymy under cognitive linguistics perspective is regarded as a cognitive process and phenomena, which also is a kind of specific expression of people's thinking. 


\section{THE ESSENCE AND COGNITION OF METONYMY BASED ON THE PERSPECTIVE OF COGNITIVE LINGUISTICS}

\section{The nature of metonymy}

Under the perspective of cognitive linguistics, metonymy is referred to as a language phenomenon, and is also regarded as a kind of way of thinking of people. Cognitive linguists define metonymy on the level of thinking, and they think that metonymy is a way and process of people's thinking, which actives the ideological essence of thinking activity in whole or in part. In simple terms, metonymy under the perspective of cognitive linguistics can arouse people's thinking activity, drive people's action, and is not simple things' nominal substitution. In Chinese culture, for example, the terms and acronyms of foods people enjoy have completely different meanings and concepts. Southerners like to eat rice, for example, while the northern people like to eat noodles. But as Chinese, we all use the word "have meals" instead of rice or noodles. Foods are the name of all the food they eat. Metonymy under cognitive linguistics perspective can achieve a representative name in a category for the full range, and make the name in the full range be representative and typical [3] This shows from another aspect that metonymy can be as a conceptual phenomenon in language use.

In the perspective of cognitive linguistics, metonymy is defined as a kind of cognitive processes and activities of thinking. In traditional rhetoric, metonymy is seen as a substitute. Under the perspective of cognitive linguistics, metonymy is a cognitive process and a communication bridge between tenor \& vehicle of metaphor. Essentially, metonymy is also regarded as a cognitive phenomenon, which uses a feature or contacting things to represent the holistic character of the things. Rhetoricians study metonymy and define metonymy as a relationship of metonymy. This relationship is not only a simple alternative, but also a relationship between things, which basically reflects the cognitive process in people's thinking and the process of perception of the world. For example, I like Beethoven. The simple words not only contain the meaning that I like Beethoven, also include the meaning that I like the personality and music works of Beethoven. Beethoven here represents the overall concept. This sentence contains a deep metonymy process, which is a cognitive process. The cognitive entity in the sentence is music and cognitive tool is Beethoven. There is a close relationship between two things and they are in the same conceptual level. But Beethoven this concept entity has more highlights, therefore in the process of the whole things cognition; people often refer to their own cognitive process to achieve overall cognition of things. In the metonymy relationship, Beethoven's music contains the characteristic of additive concepts, and the characteristic embodies people's cognitive process and cognitive phenomenon.

\section{The psychological basis of metonymy}

Cognitive linguistics metonymy study is based on Empiricism. It thinks that people's cognitive process and phenomena are based on experience and language comes from the accumulation and organizations of people's objective experience world, and there is no relationship between language and the external world. The study of metonymy under cognitive linguistics shows that the psychological basis of cognitive processes is a kind of image schema and this kind of schema can be shown in the brain [4].

\section{The cognitive mechanism of metonymy}

There is an idealized cognitive model in the operation background of metonymy, which is the knowledge representation of the brain world and forms a cultural pattern, expressing people's views on the objective world and their own understanding of things. People's Daily conversation often involves the idealized model. For example A asks B: "how did you get here?" B answers: "I came by bus." By bus also includes a series of actions and behaviors such as wait for buses, get on the bus, insert coins and so on, and B answered with idealized cognitive model. The thinking implies metonymy.

Under the perspective of cognitive linguistics, the relationship between metonymy things corresponds to each other and is conducted in the same field. Under the perspective of cognitive linguistics, metonymy process is generally according to the principle of approaching or highlight. In 
the process of metonymy, if unified cognition process is in two different categories, this principle is approaching. In a certain category, the higher is highlights degree, the wider is the activate target range. For example in daily communication: "our company has a few new faces", in which the process of metonymy is metonymy between "face" and "people". "Face" is a larger range, and "people" is the goal of metonymy. "Face" is a mapping of "people", and "face" is more prominent among numerous factors.

\section{METONYMY'S INFLUENCE ON LANGUAGE PHENOMENON BASED ON THE PERSPECTIVE OF COGNITIVE LINGUISTICS}

Rhetoric research on metonymy is mainly limited in vocabulary level, and sees metonymy as a kind of substitute, but metonymy under the perspective of cognitive linguistics has diversified functions, both fills the gaps in vocabulary, and enhances the social function of language communication.

\section{Rhetorical function}

Metonymy is a dominant trait in things to replace the overall characteristics of things, and in actual application, it enhances the effect of language expression. For example, "Grey hairs should be respected. (The old man should be respected)". This sentence not only uses metonymy form to achieve economical and practical expression, and the use of metonymy expresses rich image and impressive. This sentence expresses that the old man should be respected, in which the old man is expressed in a sentence with "Grey hairs", which implies the dominant characteristic of the characters, and it is easy to be understood. In Chinese there are many uses of metonymy, such as in "The Water Margin", one of the four great classics in China, the names of the characters are expressed in highlights nickname to express rhetorical effect, such as Lu Zhishen is called "rude monk", and Song Jiang is known as "timely rain", etc. These titles contain the dominant characteristics of the characters and can achieve effective rhetoric effect.

\section{Linguistic function}

Under the perspective of cognitive linguistics, metonymy is defined as a cognitive process and phenomenon of thinking, namely people's connections with things nearby in unified fields, and understands the unknown phenomenon through cognitive phenomenon. Therefore in the process of new words generation, metonymy plays a very important role. Metonymy plays an important role in the creation of new words, and uses the characteristics of the things in the creation of new words [5], such as sunflower, azalea, etc. Metonymy in word meaning variation is mainly to derive different similar meanings through familiar variations. Create a link between things in cognitive domain and realize the mutual replacement so as to expand or narrow the scope of words meaning. "River" is originally "Yellow River", for example, and "river" is Yangtze River. Gradually the scopes of these two words meaning are expanding now. "Gold" in Chinese generally refers to all metal objects, but with the development of the language, "gold" is specifically gold. Metonymy not only can expand the scope of narrow meaning, also can undertake anti-sense of words and the transfer of part of speech. In the same cognitive domain, there is interdependence and contradictory relationship between all elements, such as the meaning of "toughness" in Chinese means tough. It also has the meaning of flexibility and the meaning of both governance and disorder. "Smelly" in ancient Chinese means smell and aroma and noxious gas can both use this word, but with the development, the word is gradually applied to noxious gas. Metonymy can also transfer part of speech to strengthen the function of language. For example, the word "fishing" belongs to the idealized cognitive model, including a series of actions such as put bait, put on the line, etc., and is usually used to express a series of function and complete a series of action cognitive activities.

\section{Social function}

Under the perspective of cognitive linguistics, metonymy has social function. People in daily life often use the related things to replace some of the things due to some taboos and inconvenience to mention it to complete language expression. Metonymy process can make the language expression more tactful and promote social relations. In discussing someone got an incurable disease, for example, Chinese often use: "He had a bad disease." Bad disease is to take care of the sick person's 
state of mind and emotional needs, or to take care of others' face and not to mention the name of the disease. The use of bad disease, such euphemism words, can strengthen the relationship between people.

\section{CONCLUSION}

With the gradual development of cognitive linguistics, linguistic research on metonymy is gradually rising, and the research process transforms from traditional rhetoric to the study under the perspective of cognitive linguistics. Through cognitive linguistics, the diversity and function of metonymy are analyzes to explore the influence of metonymy in language phenomenon and its development trend and provide reference value for linguistic study.

\section{AUTHOR INTRODUCTION}

Wang Jiaoyan (1981 -), female, Han, Hubei Dangyang, master, lecturer, research direction: linguistics and applied linguistics

Detailed address: Foreign Languages Department, Jingchu University of Technology, No. 33 Xiangshan road, Dongbao district, Jingmen, Hubei

Phone: 13451162981

\section{REFERENCES}

[1] Cao Shiyi. Metonymy under the framework of cognitive linguistics [J]. Journal of Xiangtan University (Philosophy and Social Sciences Edition), 2014, 42 (5) : 137-140.

[2] Wang Yin. Significance binary, meaning view and awareness ---- a new understanding of "one thing with more than one names" based on experience philosophy [J]. Journal of PLA Foreign Languages Institute, 2011 (5) : 1-6.

[3] Yuan Ye. Construction Grammar, languages suppress phenomenon and metonymy rhetoric [J]. Journal of Contemporary Rhetoric, 2010, (3) : 40-48.

[4] Wei Zaijiang. Textual metonymy review [J]. Journal of Foreign Languages, 2007, (3) : 32 to 37.

[5] Yin Bochun. Language unit metonymy and language integration ---- about the differences between conceptual metaphor, conceptual metonymy and conceptual integration[J]. Journal of Hunan Radio and Television University, 2015, (1) : 30-34. 